\title{
Investigating the periodicities of the Turkish food inflation with considering the subgroups
}

\author{
Kâmil Demirberk ÜNLÜ ${ }^{*}$, Cem BAŞ², \\ Yılmaz AKDI ${ }^{3}$, Yunus Emre KARAMANOĞLU ${ }^{4}$ \\ ${ }^{1}$ Atilim University, Department of Mathematics Ankara, Turkey. \\ ${ }^{2}$ Turkish Statistical Institute (TURKSTAT), Ankara, Turkey. \\ ${ }^{3}$ Department of Statistics, Faculty of Science, Ankara University, Ankara, Turkey \\ ${ }^{4}$ Gendarmerie and Coast Guard Academy, Ankara, Turkey \\ Gelis Tarihi (Received Date): 11.04.2021 \\ Kabul Tarihi (Accepted Date): 11.10.2021
}

\begin{abstract}
This paper empirically identifies the hidden periodicities in the time series of monthly food inflation of Turkey with its subgroups for the periods from January, 2004 to June, 2020. Periodicity is the hidden cycles of the time series which is beyond the seasonality. In order to deal with this hidden cycles periodogram based time series analysis is used. Also, future inflation ratios are forecasted by Harmonic regression. The results of this study reveal that food inflation of Turkey has cycles of approximately 2 years which is mostly derived by food and non-alcoholic beverage inflation.
\end{abstract}

Keywords: Harmonic regression, periodogram, food inflation, subgroups of inflation, Turkey

\section{Türkiye g1da enflasyonunun dönemselliklerinin alt gruplar dikkate alınarak incelenmesi}

$\ddot{O} z$

Bu makale, Ocak 2004 - Haziran 2020 dönemleri için Türkiye aylık gıda enflasyonu zaman serilerindeki gizli periyodiklikleri alt gruplart ile ampirik olarak tanımlamaktadır. Dönemsellik, mevsimselliğin ötesinde olan zaman serilerinin gizli döngüleridir. Bu gizli döngülerle başa çıkmak için periodogram tabanlı zaman serisi

"Kâmil Demirberk ÜNLÜ, demirberk.unlu @atilim.edu.tr, https://orcid.org/0000-0002-2393-6691

Cem BAŞ, cem.bas@tuik.gov.tr, https://orcid.org/0000-0003-4488-2562

Y1lmaz AKDİ, yilmaz.akdi@ ankara.edu.tr, https://orcid.org/0000-0003-0188-0970

Yunus Emre KARAMANOĞLU, eyunus@bilkent.edu.tr, http://orcid.org/0000-0001-9711-6867 
analizi kullanılır. Ayrıca, gelecekteki enflasyon oranları harmonik regresyon ile tahmin edilmektedir. Bu çalışmanın sonuçları, Türkiye gıda enflasyonunun yaklaşık 2 yıllık döngülere sahip olduğunu ve bunun çoğunlukla glda ve alkolsüz içecek enflasyonundan kaynaklandığını ortaya koymaktadır.

Anahtar kelimeler: Harmonik regresyon, periodogram, glda enflasyonu, enflasyonun alt gruplarl, Türkiye.

\section{Introduction}

Inflation refers to the continuous and general increase observed in the prices of goods and services in an economy. The costs of inflation are important not only for individuals and companies, but also for society and the economy as a whole. Inflation deeply affects the decision-making process of consumers and investors. The constant and fluctuating increase in prices makes it difficult for consumers to compare different goods and services and therefore choose the product to buy. This situation may cause the consumers can restrict their consumption and postpone their investments and companies cannot foresee their costs and profits in the future. Inflation concerns daily life in many ways. Interest on deposits, on which households and firms make use of their savings, interest on loans used to purchase goods and services, salaries and wages received for work, social security premiums and pensions are directly affected by the increase in inflation. In this context, the Consumer Price Index is the most important indicator of inflation.

The Consumer Price Index (CPI) is an indicator of price changes for goods and services subject to household consumption expenditures over time. The main purpose of the 2003 base year CPI is to calculate the inflation rate by measuring the change in the prices of all goods and services subject to consumption in the market. For this purpose, the CPI takes into account all final domestic monetary consumption expenditures of foreign visitors and institutional population, as well as households.

CPI calculations are carried out in three stages:

1) forming the consumption basket,

2) determining the weight of the goods and services in the basket,

3) compiling the prices.

The $2003=100$ base year CPI is calculated as a chain index and the goods and services included in the CPI basket are composed to reflect the most up-to-date consumption structure of households. In this context, goods and services that have an increasing weight in household expenditures each year are included in the index basket, while products with a decreasing weight are excluded from the basket.

The main data source for determining the goods and services to be included in the CPI consumption basket and calculating the weights is the Household Budget Survey (HBA), which compiles household consumption expenditures. As determined by the European Union Statistics Office (EuroStat), goods and services weighting more than 1/1000 in total household consumption expenditures are included in the CPI basket. In addition to the HBA, individual consumption expenditures of the institutional 
population and expenditures made by foreign visitors and administrative records are also used in the creation of consumption baskets and weights.

The item basket and the weights are updated at the end of each year and the series are continued by using chained Laspeyres formula. The index is calculated by dividing the current prices by the prices of the previous December, which is the "new price reference period $\left(\mathrm{P}_{0}\right)$, and then chained by multiplying it with the December index. Cash prices including all taxes reflected on the consumer are compiled and item type prices are calculated with the geometric average in CPI calculations.

The main consumption group that has the highest weight in the CPI consumption basket is "Food and non-alcoholic beverages", in line with the "hierarchy of needs" concept defined by Maslow in the 1950s. The weight of this main expenditure group, which is essential to support the physiological needs of each individual, regardless of the socioeconomic status is $22.77 \%$ for 2020 , although it has decreased slightly due to the changes in the consumption patterns of households over time and the relative increases in the weight of other expenditure groups. Due to its aforementioned importance, 134 of the total 418 items (32.1\%) in the CPI basket are foodstuffs and non-alcoholic beverages. Fresh vegetables and fruits and other food prices included in the CPI consumption basket are compiled every week to reflect the price fluctuations in the market and great emphasis is placed on the same item definitions in order to ensure accurate price collection.

Both periodic movements in food prices and the high weight structure in the consumer basket of food prices in Turkey causes volatility and big effect in general level. Food products under consumer prices can be grouped under two groups as processed and unprocessed and special CPI indicators divide the main group of food and non-alcoholic beverages into two parts: 1) processed food products and, 2) unprocessed food products.

Unprocessed food products include products such as fruits, vegetables, meat and fish, which are offered directly to household consumption without any special processing. On the other hand, processed food products are products such as meat products such as fruit juices, salami, sausage, or dairy products such as cheese, yoghurt offered to households after passing through a certain process and value-added chain. Processed food products are divided into two parts: fresh fruits-vegetables and other products, while unprocessed food products are divided into two parts: bread-cereals and other.

Food and non-alcoholic beverages main group consists of 36 COICOP 5 subgroups in total. 12 subgroups are included in the unprocessed food products and 24 subgroups are included in the processed food products.

Processed foods include rice, all kinds of fresh meats (veal, sheep, poultry, fish), eggs, milk, fresh fruits, vegetables, potatoes, dried vegetables and fruits.

Unprocessed foods include breads, flours, pasta, dried-smoked-salted meats, cheese, butters, margarines, oil-sunflower-corn oils, dried-preserved-processed vegetables, jams, chocolate, ice creams, tea, coffee, soft drinks and juices. Table 1 gives the detail of weight structure of food and non-alcoholic beverages between the years 2013-2020. 
Table 2 gives detailed structure and weight of 2020 unprocessed food. Table 3 gives detailed structure and weight of 2020 processed food. The abbreviations written in Table 2 and Table 3 detail columns are given in Table 1 group column.

UPF shows the unprocessed foods and this group divided two braches; FV (fresh fruits and vegetables) and OUPF (other unprocessed foods). PF shows the processed foods and this group also divide into two branches; BC (bread and cereals) and OPF (other processed foods).

Table 1. 2020 weight structure of indicators for the CPIs having specified coverages

\begin{tabular}{|l|l|l|l|c|c|c|c|c|l|}
\hline Group & Coverage & $\mathbf{2 0 1 3}$ & $\mathbf{2 0 1 4}$ & $\mathbf{2 0 1 5}$ & $\mathbf{2 0 1 6}$ & $\mathbf{2 0 1 7}$ & $\mathbf{2 0 1 8}$ & $\mathbf{2 0 1 9}$ & $\mathbf{2 0 2 0}$ \\
\hline & $\begin{array}{l}\text { Food and non- } \\
\text { alcoholic beverages }\end{array}$ & 24.09 & 24.45 & 24.25 & 23.68 & 21.77 & 23.03 & 23.29 & 22.77 \\
\hline UPF & Unprocessed food & 10.67 & 11.50 & 11.21 & 11.21 & 10.29 & 11.31 & 11.29 & 10.72 \\
\hline FV & $\begin{array}{l}\text { Fresh fruits and } \\
\text { vegetables }\end{array}$ & 4.32 & 4.34 & 3.98 & 4.43 & 3.52 & 4.22 & 4.15 & 3.66 \\
\hline OUPF & $\begin{array}{l}\text { Other unprocessed } \\
\text { food }\end{array}$ & 6.35 & 7.16 & 7.23 & 6.78 & 6.77 & 7.09 & 7.14 & 7.06 \\
\hline PF & Processed food & 13.42 & 12.95 & 13.04 & 12.48 & 11.49 & 11.73 & 12.00 & 12.05 \\
\hline BC & Bread and cereals & 5.05 & 4.88 & 4.81 & 4.41 & 4.18 & 4.07 & 4.17 & 4.24 \\
\hline OPF & Other processed food & 8.37 & 8.07 & 8.23 & 8.07 & 7.30 & 7.66 & 7.83 & 7.81 \\
\hline
\end{tabular}

Table 2. 2020 weight structure and detail of unprocessed food

\begin{tabular}{|l|l|l|l|}
\hline COICOP LEVEL 5 & Unprocessed Food & Detail & Weight \\
\hline 01161 & Fresh or chilled fruit & FV & 1.5209 \\
\hline 01171 & Fresh or chilled vegetables other than potatoes and other tubers & FV & 2.1391 \\
\hline 01111 & Rice & OUPF & 0.3077 \\
\hline 01122 & Beef and veal & OUPF & 2.1483 \\
\hline 01124 & Lamb and goat & OUPF & 0.977 \\
\hline 01125 & Poultry & OUPF & 0.8327 \\
\hline 01131 & Fresh or chilled fish & OUPF & 0.3546 \\
\hline 01141 & Milk, whole, fresh & OUPF & 0.6925 \\
\hline 01145 & Cheese and curd & OUPF & 0.466 \\
\hline 01162 & Dried fruit and nuts & OUPF & 0.8044 \\
\hline 01172 & Dried vegetables, other preserved or processed vegetables & OUPF & 0.2197 \\
\hline 01174 & Potatoes & OUPF & 0.2551 \\
\hline
\end{tabular}

Table 3. Weight structure and detail of processed food

\begin{tabular}{|l|l|l|l|}
\hline COICOP LEVEL 5 & Processed Food & Detail & Weight \\
\hline 01112 & Flours and other cereals & BC & 0.6246 \\
\hline 01113 & Bread & BC & 2.1738 \\
\hline 01114 & Other bakery products & BC & 1.2342 \\
\hline 01115 & Pasta products and couscous & BC & 0.1828 \\
\hline 01116 & Breakfast cereals & BC & 0.0226 \\
\hline 01126 & Edible offal & OPF & 0.0397 \\
\hline 01127 & Dried, salted or smoked meat & OPF & 0.4788 \\
\hline 01143 & Other milk products & OPF & 0.5426 \\
\hline
\end{tabular}


Table 3. (Continued).

\begin{tabular}{|l|l|l|l|}
\hline 01144 & Cheese & OPF & 1.3540 \\
\hline 01151 & Butter & OPF & 0.3178 \\
\hline 01152 & Margarine and other vegetable fats & OPF & 0.0633 \\
\hline 01153 & Olive oil & OPF & 0.8269 \\
\hline 01175 & Crisps & OPF & 0.7829 \\
\hline 01181 & Sugar & OPF & 0.3762 \\
\hline 01182 & Jams, marmalades and honey & OPF & 0.3440 \\
\hline 01183 & Chocolate & OPF & 0.5284 \\
\hline 01184 & Confectionery products & OPF & 0.1981 \\
\hline 01190 & Other food products & OPF & 0.3154 \\
\hline 01211 & Coffee & OPF & 0.1340 \\
\hline 01212 & Tea & OPF & 0.5848 \\
\hline 01213 & Cocoa and powdered chocolate & OPF & 0.0113 \\
\hline 01221 & Mineral or spring waters & OPF & 0.4431 \\
\hline 01222 & Soft drinks & OPF & 0.3187 \\
\hline 01223 & Fruit and vegetable juices & OPF & 0.1324 \\
\hline 01133 & Canned or processed fish products & OPF & 0.0201 \\
\hline
\end{tabular}

The food subgroup constitutes approximately $93 \%$ of the food and non-alcoholic beverages main group and therefore has a structure that directly affects the main group.

The share of processed food products in the food and non-alcoholic beverages main group is high. The most effective groups for the unprocessed food group are fresh vegetables, veal and fresh fruits. The most effective groups for the processed food group are bread, cheese and other bakery products (biscuit, cracker, wafer etc.).

The food group constitutes approximately one-fifth of the consumer basket and this weight structure makes food price movements very important. For that reason, in order to stabilize the inflation, understanding the underlying factors of food inflation is important. Possible cycles and price movements of the food inflation may trigger the base inflation, moreover the price changes in food inflation is one of the main factors which effects the public wealth. Based on this, this article attempts to determine the effect of price movements and periodicity in processed and unprocessed products and food on consumer price inflation. The reasons for the instability in the prices of food products, such as restrictions in product supply due to drought and natural disasters caused by global warming, increases in production and transportation costs due to the increase in oil prices and changes in input costs due to exchange rates can be listed as the main factors causing volatility in agriculture and food prices.

Achieving price stability will be possible primarily by establishing a stable structure in all processes of the food sector. Periodicity and fluctuations in food prices affect the entire economy, for this reason, government should follow effective policies for the agricultural and food products markets. The fact that processed food products are not stable can be considered as a reflection of market pricing strategies. For that reason, our aim in this study is to identify the periodic structure of food inflation with their sub groups. To achieve this goal, we will employ time series depends on periodograms which are used to identify hidden cycles in the time series. These cycles are called 
periodicities. They are different than seasonality, they can be defined as the hidden cycles in the data. It is important to identify and use these cycles to have accurate projections and planning. The finding of these study reveals the unit root structure of food inflation with its periods.

The rest of the paper is as follows: In Section 2 we briefly give the literature about both food inflation and time series based on periodograms. Section 3 is devoted to the methodology. Experimental setup with empirical results are given in Section 4. Lastly, conclusion given in Section 5.

\section{Literature review}

Lamm [20] analyzed the effects of higher form product prices on food prices using Pascal distributed lag models of the price adjustment process. As an explanation for the increases in food prices in recent years, it introduces the concept of a change in the supply of food price inflation. This view is consistent with cost-driving theories of inflation. Estimates are offered for 23 selected food products. As a result, it is shown that higher farm prices for highly unprocessed food products are most rapidly being transferred to the retail level.

Vann [25] investigated a hypothesis about the formation of inflation expectations and it was observed that economic units attach more weight to the final behavior of food prices than their spending shares while forming expectations. This hypothesis is called the biased expectations hypothesis (BEH). Using the stochastic fixed price-flexible price model of the US economy, the effects of $\mathrm{BEH}$ on the general inflation rate are derived and it is shown that the bias in the formation of expectations can be Multirational.

Hafer and Hein [13] compared the accuracy of three different inflation forecasting procedures. These are the univariate time series model, an interest rate model based on the Fama and Gibbons methodology, and median estimates from the American Statistical Association-National Bureau of Economic Research survey. The data is based on estimates of quarterly inflation rates using the GNP deflator for the period 1970:I-1984:II. As a result, survey estimates have been shown to offer the most accurate inflation estimates.

Franses and Ooms [10] formed an extension of the fractional integrated ARIMA ( $0, d$, 0 ) model for quarterly UK inflation. They allow the fractional integration parameter to vary according to s season. This periodic ARFIMA model $(0, \mathrm{~d}, 0)$ not only provides an informative explanation in the sample, but can also be useful for non-sample estimates. The main result is that the integration parameter in the first two quarters is significantly larger than it was in the last two quarters.

Gómez et.al. [12] examined a study conducted in Colombia for short-term food inflation forecasts. The model separates food products according to economic theory and uses Flexible Least Squares. The performance of the new model has been compared with the existing models used by the central bank. Econometric methods have been applied by combining predictions from alternative models. As a result, it shows that forecasting can be improved by classifying food basket items by unprocessed and processed products and using estimation combination techniques. 
Altissimo et.al. [7] provides a summary of current information on inflation persistence and price stickiness in the euro area. The main findings are: i) With the current monetary policy, the estimated degree of inflation persistence in the euro area is moderate; ii) Retail prices in the euro area are stickier than in the USA; iii) There is sectoral heterogeneity in prices; iv) Price drops are not uncommon.

Bronnenberg et.al. [8] develops several empirical generalizations about the role of periodicity in pricing. (i) inter-brand correlation in prices occurs in more than one category, (ii) pricing interactions are aggregated across frequencies, hiding different and different interactions, (iii) pricing interactions are related to category and brand-specific factors such as average purchase times (iv) regular price changes. (v) periodicity can affect inferences about the nature of competition within a product category.

Safouane et.al. [22] studied how the length of the decision range for a given price period changed the dynamic characteristics of inflation and output in various New Keynesian models. The result is that higher-frequency versions of sticky information, overlapping contracts, and hybrid adhesive price models predict higher, immutable, and lower levels of inflation persistence, respectively.

Hasanov [15] used monthly data for the period 1986-2006 has estimated the impact of inflation uncertainty in Turkey to open items. The effects of uncertainty on products in the period including high and low inflation periods were evaluated. The results show that inflation uncertainty has negative and statistically significant effects on products in both high inflation and low inflation periods.

Hanif [14] studied how food inflation affects the poor at a higher rate than the rich. The rise in global food and crude oil prices in 2008 led to increased food inflation in Pakistan. However, the spread of food inflation is lower than non-food inflation in Pakistan. Volatility in food inflation in Pakistan was found to be about 50 percent of the amount observed in the world. Within the food group, most of the goods produced show the persistence of inflation. Comparing food inflation with labor wage increases, it was found that the poor (working class) were disadvantaged.

Schnepf and Richardson [24] prepared a report on retail food price inflation. During 1991-2006, data measured by the US Bureau of Labor Statistics (BLS) Consumer Price Index (CPI) were used. The report examines the economic factors that gradually increased market prices for unprocessed agricultural products, energy costs and retail food prices in late 2005. As a result, it is shown that agricultural product prices are significantly more volatile than other marketing and processing costs that fall into the retail or ready-to-eat food class.

Joiya and Shahzad [18] analyzed determinants of high food prices in Pakistan using an autoregressive distributed lag approach to the model of co-integration and error correction in the long and short term, respectively. Time series data was used for the period 1972-1973 and 2009-2010. Empirical findings suggest that all determinants are crucial both in the long term and in the short term. GDP and food exports contribute to high food prices, while food imports and credit to the agricultural sector lead to a decline in food prices. Import prices cause a drop in food prices, then a balance of payments problem due to a trade deficit. 
Durevalla et.el. [6] using monthly data from the last decade in Ethiopia, estimated inflation models to determine the importance of factors contributing to CPI inflation and its three main components: (i) grain prices, (ii) food prices, and (iii) non-food prices. The main finding is that movements in international food and goods prices, measured in domestic currency, determine the long-term evolution of domestic prices. In the short term, agricultural supply shocks affected food inflation, causing major deviations from long-term price trends. Our results suggest that world food prices and domestic agricultural production should be considered when analyzing inflation in emerging economies, which have a large share of food in consumer prices.

Agrawal and Kumarasamy [6] analyzed the food demand and supply in India in terms of local policies needed to control food inflation. It categorized the food demand in India (cereals, vegetables, fruits, etc.) and predicted it by 2025 . It is seen that food inflation is mainly due to changing patterns of food demand. This is combined with structural problems that prevent adequate supply-side responses to changing consumption patterns and the inability of the government to deal with them. It has been shown that the inability to increase the agricultural land is one of the most critical problems in food inflation.

Adam et.al. [1] estimate 'multiple determinant' single equation models for inflation and its main components (food, energy and core inflation), an empirical representation of inflation in Tanzania for the decade after 2001 has been constructed. The results reveal that supply-side factors, including yield variability and international price arbitrage, play an important role in determining domestic food and fuel inflation.

Salisu and Kazeem [23] showed that commodity prices did not improve inflation estimates based on the traditional Phillips curve. A very predictive framework for U.S. inflation has been built by increasing the traditional Phillips curve with symmetrical and asymmetric oil price changes. Key determinants of U.S. inflation have been shown to exhibit the effects of persistence, endogenies, and conditional heteroscedasticity, which have effects on forecast performance.

Gil and Trani [16] examined the cyclical structure of the UK inflation rate using historical data dating back to 1210. Results for a method that allows a non-loop zero frequency and fractional stochastic integration, repeated cycles approximately every 4 years being between 0.10 and 0.15 based on the presence of a long memory, and integration scheme.

Ida [17] worked on optimal monetary policy in a New Keynesian model with continuity of sectoral inflation. It focuses on the wealth gap between timeless perspective (TP) and a purely discretionary monetary policy. In both cases, the continuity of sectoral inflation, the continuous flexibility of the substitute Consumption Index, and generalized thumb price adjustment make the central bank's optimization problem more complicated.

Kang et.al. [19] investigated the binary causality of inflation rates between time and frequencies, inflation cycle synchronization and causal network structure between five countries: Indonesia, Malaysia, Philippines, Singapore and Thailand. They get empirical results by applying dynamic conditional correlations (DCCs), a wavelet cohesion approach, and Diebold and Yilmaz's spread network index model to assess the evolution 
of the inflation cycle. They find evidence of a time-dependent shift in the strength of the joint movement between inflation cycles between countries.

Table 4 summarizes the current literature of food inflation. Our study extends the current literature by employing periodogram based time series analysis. To the best of our knowledge this is the first study which employs the methodology to investigate the hidden cycles of the food inflation of Turkey.

Table 4. Summary of the recent literature

\begin{tabular}{|l|l|c|}
\hline \multicolumn{1}{|c|}{ Location } & \multicolumn{1}{|c|}{ Methodology } & Reference \\
\hline USA & Discrete Dynamic Model & {$[20]$} \\
\hline USA & Biased Expectations Hypothesis & {$[25]$} \\
\hline USA & ARIMA,T-BILL and ASA-NBER & {$[13]$} \\
\hline UK & ARIMA & {$[10]$} \\
\hline Colombia & Various time series methodologies & {$[12]$} \\
\hline USA and Europe & Inflation Persistence Network & {$[7]$} \\
\hline USA & Spectral Decomposition & {$[8]$} \\
\hline- & Various pricing models & {$[22]$} \\
\hline Turkey & ARCH & {$[15]$} \\
\hline Pakistan & Granger Causality & {$[14]$} \\
\hline USA & - & {$[24]$} \\
\hline Pakistan & ARDL & {$[18]$} \\
\hline India & ARDL & {$[6]$} \\
\hline Pakistan & SVAR & {$[14]$} \\
\hline Tanzania & Multiple-determinant single-equation models & {$[1]$} \\
\hline USA & ARIMA and DMA & {$[23]$} \\
\hline UK & Stochastic cycles & {$[16]$} \\
\hline- & Two sector NK-model & {$[17]$} \\
\hline ASEAN countries & Dynamic conditional correlations & {$[19]$} \\
\hline
\end{tabular}

\section{Methodology}

In the methodology we will follow the procedure given in [3], which uses periodogram based time series analysis to identify the cycles in the monthly weather pollution data of Ankara, Turkey. In recent years, periodogram based time series analysis and periodogram based unit root test has many applications in energy [1] weather pollution [21] and finance and economics [5]. It is very useful and powerful modeling framework since it requires no assumption or parameter estimations except for the variance of the white noise series. In this section we will summarize the methodology more details about it can be found in [21].

In order to investigate the hidden periodicities, the investigated time series should be stationary. For that reason, we start our analysis by Augmented Dickey Fuller unit root test (ADF). Since our main aim is to identify the periodic structure of the time series, another alternative to ADF can be [2] which is a unit root test based on periodograms. Test statistics defined in [2] to investigate the unit root is given as:

$T_{n}\left(w_{k}\right)=\frac{2\left(1-\cos \left(w_{k}\right)\right.}{\widehat{\sigma}_{n}{ }^{2}} I_{n}\left(w_{k}\right)$. 
Here, the asymptotic behavior of the test statistic is $T_{n}\left(w_{k}\right) \stackrel{d}{\rightarrow} Z_{1}{ }^{2}+3 Z_{2}{ }^{2}$, as $n \rightarrow \infty$, where $Z_{1}^{2}$ and $Z_{2}^{2}$ are random variables, which has standard normal distribution. In short, the distribution of the test statistics is [11]

$$
T_{n}\left(w_{k}\right) \stackrel{d}{\rightarrow} \chi_{1}^{2}+3 \chi_{1}^{2}
$$

Asymptotic distribution is valid for all $\mathrm{k}$ values, in general $\mathrm{k}$ is set to be equal to 1 . Let denote the test statistics as $T_{n}\left(w_{k}\right)$ and if $T_{n}\left(w_{k}\right)$ is less than the critical values, we conclude that the null hypothesis is rejected. The null hypothesis of this test is time series has unit root. Critical values of the test given in [20]. Here, we list some of them.

$P(T \leq 0.034818)=0.01, P(T \leq 0.178496)=0.05$ and $P(T \leq 0.369089)=0.10$

If, $t_{n}\left(w_{1}\right)<c_{1}$ we say that the investigated time series is stationary under $\% 1$ significance level.

Periodograms are formed by trigonometric functions. Consider the trigonometric functions which are very known periodic functions. Now, let $e_{t}$ denotes the independent and identically distributed random variables with mean 0 and variance $\sigma^{2}$, consider the following model

$Y_{t}=\mu+R \cos (w t+\phi)+e_{t}, t=1,2, \ldots, n$

where $\mu, R, w$ and $\phi$ expected value, amplitude, frequency and phase respectively. If $w_{k}=2 \pi k / n$ then, we can rewrite Equation (3) as

$Y_{t}=\mu+\alpha \cos \left(w_{k} t\right)+\beta \sin \left(w_{k} t\right)+e_{t}, t=1,2, \ldots, n$.

Least square estimations of the parameters of the Model (4) are

$\hat{\mu}=\bar{Y}_{n}, a_{k}=\frac{2}{n} \sum_{t=1}^{n}\left(Y_{t}-\bar{Y}_{n}\right) \cos \left(w_{k} t\right)$ and $b_{k}=\frac{2}{n} \sum_{t=1}^{n}\left(Y_{t}-\bar{Y}_{n}\right) \sin \left(w_{k} t\right)$

On the Model (4) if the null hypothesis of $H_{0}: a=b=0$ is rejected then time series has periodic component. Since $w_{k}$ is not known, standard F-test cannot be used. Instead of F-test, Wei [26] defines the following test statistic

$V=I_{n}\left(w_{(1)}\right)\left[\sum_{k=1}^{m} I_{n}\left(w_{k}\right)\right]^{-1}$

where $I_{n}\left(w_{(1)}\right)$ represents the biggest periodicity while $m=\llbracket n / 2 \rrbracket$. Critical values of the test statistics are calculated by

$c_{\alpha}=1-(\alpha / m)^{1 /(m-1)}$ 
Here, $\alpha$ represents the significance level. If $V>c_{\alpha}$ then null hypothesis rejected. If the time series has periodic components, say $\mathrm{p}_{1}$ and $\mathrm{p}_{2}$, the harmonic regression model with periodicity can be defined as

$Y_{t}=\mu+A_{1} \cos \left(\frac{2 \pi t}{p_{1}}\right)+B_{1} \sin \left(\frac{2 \pi t}{p_{1}}\right)+A_{2} \cos \left(\frac{2 \pi t}{p_{2}}\right)+B_{2} \sin \left(\frac{2 \pi t}{p_{2}}\right) e_{t}, \quad t=1,2, \ldots, n$

The model given in the Equation 8 considers the periodicities of the time series. Thus it is more appropriate to use such models to increase the accuracy of the forecasts.

\section{Data and experimental design}

In this study we have used yearly food inflation $(\mathrm{X})$ of each months and seven subsets of the food inflation such as: food and non-alcohol beverages $\left(\mathrm{X}_{1}\right)$, unprocessed food $\left(\mathrm{X}_{2}\right)$, fruit and vegetables $\left(\mathrm{X}_{3}\right)$, other unprocessed food $\left(\mathrm{X}_{4}\right)$, processed food $\left(\mathrm{X}_{5}\right)$, bread and cereals $\left(\mathrm{X}_{6}\right)$ and other processed foods $\left(\mathrm{X}_{7}\right)$ for the periods between January 2004 and June 2020. The periodicities of the above series will be investigated and by the help of these periodicities harmonic regression models will be fitted to forecast one year ahead inflation ratios. In the first step, stationarity of these series is investigated by ADF.

The results of the ADF given in the Table 5.

Table 5. Augmented Dickey Fuller test results

\begin{tabular}{|c|c|c|}
\hline Variable & $\boldsymbol{\tau}_{\boldsymbol{\mu}}$-Statistics & p-values \\
\hline $\mathrm{X}$ & -2.028561 & 0.2745 \\
\hline $\mathrm{X}_{1}$ & -1.930864 & 0.3176 \\
\hline $\mathrm{X}_{2}$ & -2.806598 & 0.0593 \\
\hline $\mathrm{X}_{3}$ & -3.189569 & 0.0222 \\
\hline $\mathrm{X}_{4}$ & -3.868113 & 0.0027 \\
\hline $\mathrm{X}_{5}$ & -2.431893 & 0.1344 \\
\hline $\mathrm{X}_{6}$ & -2.873159 & 0.0505 \\
\hline $\mathrm{X}_{7}$ & -2.013307 & 0.2810 \\
\hline Critical Values: $1 \%-3.465997,5 \%-2.877099,10 \%-2.575143$. \\
\hline
\end{tabular}

According to the results given in Table 4 , only $\mathrm{X}_{3}$ and $\mathrm{X}_{4}$ series are stationary. To investigate the potential periodicities in the series, we also employed periodogram based unit root tests. The results of the test given in the Table 6 .

Table 6. Periodogram based unit root test

\begin{tabular}{|l|c|c|c|l|l|}
\hline \multicolumn{1}{|c|}{ Variable } & \multicolumn{1}{c|}{$I_{n}\left(w_{1}\right)$} & \multicolumn{1}{c|}{$\hat{\sigma}_{n}^{2}$} & $t_{n}\left(w_{1}\right)$ & \multicolumn{1}{c|}{ Decision } & \multicolumn{1}{c|}{ Lag Order } \\
\hline $\mathrm{X}$ & 415.18 & 5.319356 & 0.078591 & Stationary & $\mathrm{P}=(1)$ \\
\hline $\mathrm{X}_{1}$ & 451.26 & 6.242809 & 0.072785 & Stationary & $\mathrm{P}=(1,6,8,13)$ \\
\hline $\mathrm{X}_{2}$ & 212.88 & 5.099336 & 0.042035 & Stationary & $\mathrm{P}=(1,6,8,13)$ \\
\hline $\mathrm{X}_{3}$ & 638.79 & 127.2854 & 0.005053 & Stationary & $\mathrm{P}=(1,2,6,8,10,13)$ \\
\hline
\end{tabular}


Table 6. (Continued).

\begin{tabular}{|l|l|l|l|l|l|}
\hline $\mathrm{X}_{4}$ & 77.02 & 6.112184 & 0.012688 & Stationary & $\mathrm{P}=(1,2,4,8,13)$ \\
\hline $\mathrm{X}_{5}$ & 725.28 & 0.776442 & 0.940570 & Not Stationary & $\mathrm{P}=(1,2,3,12)$ \\
\hline $\mathrm{X}_{6}$ & 430.13 & 1.183937 & 0.365820 & Not Stationary & $\mathrm{P}=(1,2,13)$ \\
\hline $\mathrm{X}_{7}$ & 1025.94 & 0.75406 & 1.369960 & Not Stationary & $\mathrm{P}=(1,2,3,12,13)$ \\
\hline
\end{tabular}

Critical Values: $1 \% 0.034818,5 \% 0.178496,10 \% 0.369089$.

Periodogram based unit-root test needs the variance of the white noise of each investigated time series. In order to find the variance of the white noise ARIMA models of each series are estimated. Best models are chosen by minimizing the Akaike Information Criteria and investigating the partial autocorrelation functions. The selected lags of the ARIMA models are given in the above table. Also, note that according to the periodogram based unit root test indicate that food inflation is stationary but this not the case when ADF is considered. From Table 5 it can be easily seen that $X, X_{1}, X_{2}, X_{3}$ and $\mathrm{X}_{4}$ are stationary while $\mathrm{X}_{5}, \mathrm{X}_{6}$ and $\mathrm{X}_{7}$ has unit roots. Processed foods $\left(\mathrm{X}_{5}, \mathrm{X}_{6}\right.$ and $\left.\mathrm{X}_{7}\right)$ are not stationary since $t_{n}\left(w_{1}\right)$ statistics of these series are greater than $\% 5$ critical level. For that reason, we are not going to investigate the non-stationary time series.

In table $4, \mathrm{ADF}$ test indicates that $\mathrm{X}, \mathrm{X}_{1}$ and $\mathrm{X}_{2}$ are not stationary, but periodogram based unit root test shows that these series are stationary since the test statistics $t_{n}\left(w_{1}\right)$ are less than the 5\% critical values. For that reason, we consider these series as stationary series and we will continue to investigate them. Time series graphs of stationary series with their partial autocorrelations are given in Figure 1. 
BAUN Fen Bil. Enst. Dergisi, 24(1), 232-250, (2022)

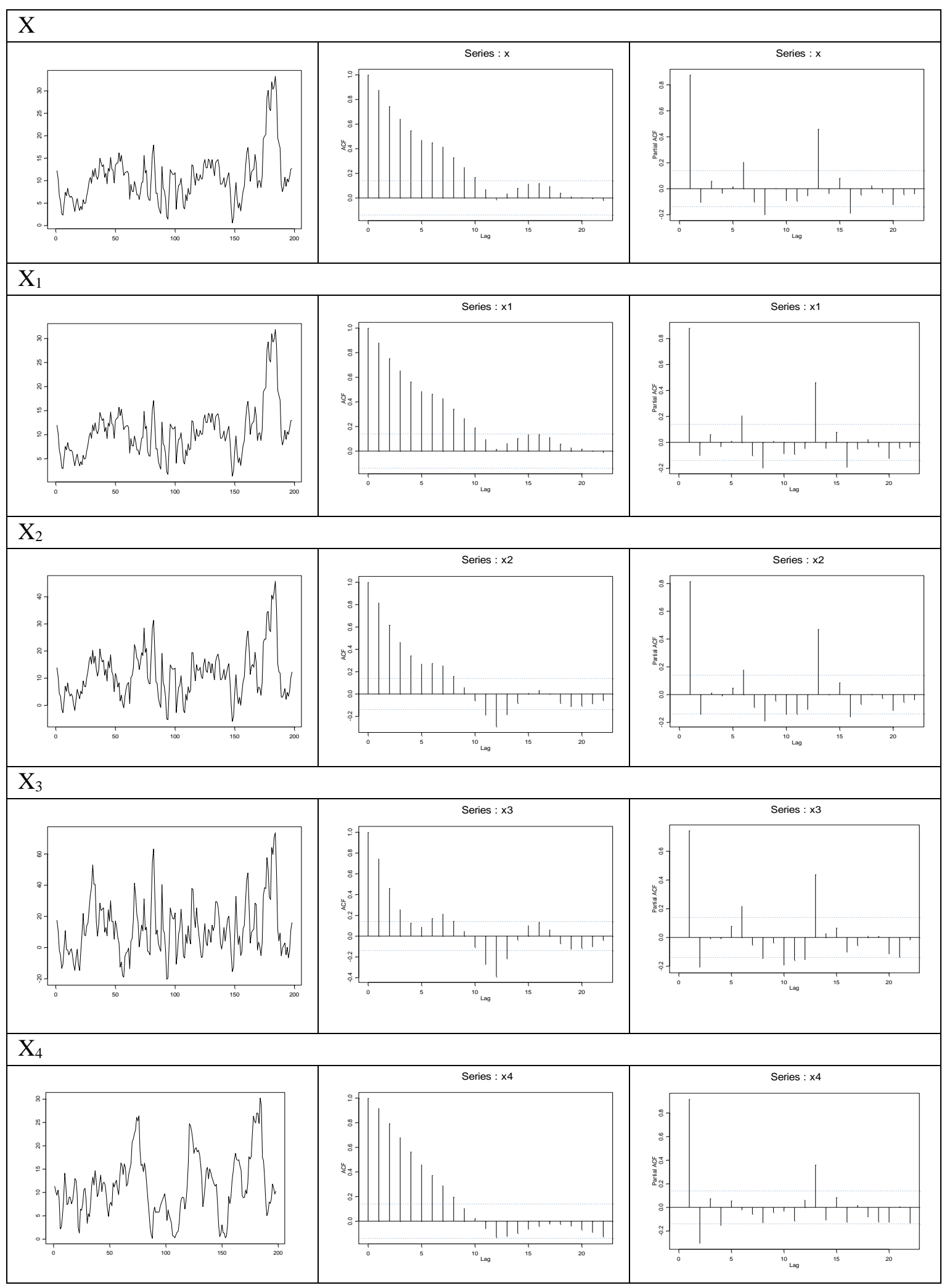

Figure 1. Time series graphs of stationary series

Periods corresponding to five biggest periodogram value with their $\mathrm{V}_{\mathrm{i}}$ are statistics are given in the Table 7 . 
Table 7. Periods of five biggest periodogram with their test statistics

\begin{tabular}{|c|c|c|c|c|c|}
\hline \multicolumn{3}{|l|}{$\mathbf{X}_{1}$} & \multicolumn{3}{|l|}{$\mathbf{X}_{2}$} \\
\hline$I_{n}\left(w_{(i)}\right)$ & $V_{i}$ & Periods & $I_{n}\left(w_{(i)}\right)$ & $V_{i}$ & Periods \\
\hline 1622.955 & 0.2798 & 66.000 & 4364.772 & 0.2749 & 49.50 \\
\hline 895.110 & 0.2143 & 49.500 & 1360.801 & 0.1182 & 22.00 \\
\hline 486.318 & 0.1481 & 99.000 & 1151.408 & 0.1134 & 99.00 \\
\hline 451.257 & 0.1614 & 198.00 & 1045.895 & 0.1162 & 19.80 \\
\hline 295.195 & 0.1259 & 24.750 & 950.339 & 0.1195 & 66.00 \\
\hline \multicolumn{3}{|c|}{$\mathbf{X}_{3}$} & \multicolumn{3}{|l|}{$\mathbf{X}_{4}$} \\
\hline 10446.46 & 0.1654 & 49.50 & 2377.708 & 0.2839 & 49.500 \\
\hline 5846.73 & 0.1109 & 16.50 & 1359.934 & 0.2268 & 66.000 \\
\hline 5174.12 & 0.1104 & 22.00 & 853.814 & 0.1842 & 99.000 \\
\hline 4715.39 & 0.1131 & 66.00 & 729.078 & 0.1928 & 19.800 \\
\hline 4423.66 & 0.1197 & 7.920 & 654.344 & 0.2143 & 28.286 \\
\hline \multicolumn{6}{|l|}{$\mathrm{X}$} \\
\hline 1789.841 & 0.2793 & 66.000 & & & \\
\hline 1026.003 & 0.2221 & 49.500 & & & \\
\hline 510.759 & 0.1421 & 99.000 & & & \\
\hline 415.179 & 0.1347 & 198.00 & & & \\
\hline 333.520 & 0.1250 & 24.750 & & & \\
\hline
\end{tabular}

Critical Values: \%1 0.089, \%5 0.074, \%10 0.068.

From the above Table we can conclude that all periods are statistically significant. Harmonic regression model given in the Equation 3 are as follows:

$$
\begin{aligned}
X_{t}= & \mu+A_{1} \cos \left(\frac{2 \pi t}{66}\right)+B_{1} \sin \left(\frac{2 \pi t}{66}\right)+A_{2} \cos \left(\frac{2 \pi t}{49.5}\right)+B_{2} \sin \left(\frac{2 \pi t}{49.5}\right)+A_{3} \cos \left(\frac{2 \pi t}{99}\right)+B_{3} \sin \left(\frac{2 \pi t}{99}\right) \\
& +A_{4} \cos \left(\frac{2 \pi t}{198}\right)+B_{4} \sin \left(\frac{2 \pi t}{198}\right)+A_{4} \cos \left(\frac{2 \pi t}{24.75}\right)+B_{5} \sin \left(\frac{2 \pi t}{24.75}\right)+e_{t}, \quad t=1,2, \ldots, n \\
X_{1, t}= & \mu_{1}+A_{1} \cos \left(\frac{2 \pi t}{66}\right)+B_{1} \sin \left(\frac{2 \pi t}{66}\right)+A_{2} \cos \left(\frac{2 \pi t}{49.5}\right)+B_{2} \sin \left(\frac{2 \pi t}{49.5}\right)+A_{3} \cos \left(\frac{2 \pi t}{99}\right)+B_{3} \sin \left(\frac{2 \pi t}{99}\right) \\
& +A_{4} \cos \left(\frac{2 \pi t}{198}\right)+B_{4} \sin \left(\frac{2 \pi t}{198}\right)+A_{4} \cos \left(\frac{2 \pi t}{24.75}\right)+B_{5} \sin \left(\frac{2 \pi t}{24.75}\right)+e_{t}, \quad t=1,2, \ldots, n \\
X_{2, t}= & \mu_{2}+A_{1} \cos \left(\frac{2 \pi t}{49.5}\right)+B_{1} \sin \left(\frac{2 \pi t}{49.5}\right)+A_{2} \cos \left(\frac{2 \pi t}{22}\right)+B_{2} \sin \left(\frac{2 \pi t}{22}\right)+A_{3} \cos \left(\frac{2 \pi t}{99}\right)+B_{3} \sin \left(\frac{2 \pi t}{99}\right) \\
& +A_{4} \cos \left(\frac{2 \pi t}{19.8}\right)+B_{4} \sin \left(\frac{2 \pi t}{19.8}\right)+A_{5} \cos \left(\frac{2 \pi t}{66}\right)+B_{5} \sin \left(\frac{2 \pi t}{66}\right)+e_{t}, \quad t=1,2, \ldots, n \\
X_{3, t}= & \mu_{3}+A_{1} \cos \left(\frac{2 \pi t}{49.5}\right)+B_{1} \sin \left(\frac{2 \pi t}{49.5}\right)+A_{2} \cos \left(\frac{2 \pi t}{16.5}\right)+B_{2} \sin \left(\frac{2 \pi t}{16.5}\right)+A_{3} \cos \left(\frac{2 \pi t}{22}\right)+B_{3} \sin \left(\frac{2 \pi t}{22}\right) \\
& +A_{4} \cos \left(\frac{2 \pi t}{66}\right)+B_{4} \sin \left(\frac{2 \pi t}{66}\right)+A_{5} \cos \left(\frac{2 \pi t}{7.92}\right)+B_{5} \sin \left(\frac{2 \pi t}{7.92}\right)+e_{t}, \quad t=1,2, \ldots, n
\end{aligned}
$$




$$
\begin{aligned}
X_{4, t}= & \left.\mu_{4}+A_{1} \cos \left(\frac{2 \pi t}{49.5}\right)+B_{1} \sin \left(\frac{2 \pi t}{49.5}\right)+A_{2} \cos \left(\frac{2 \pi t}{66}\right)+B_{2} \sin \left(\frac{2 \pi t}{66}\right)+A_{3} \cos \left(\frac{2 \pi t}{99}\right)+B_{3} \sin \left(\frac{2 \pi t}{99}\right)\right) \\
& +A_{4} \cos \left(\frac{2 \pi t}{198}\right)+B_{4} \sin \left(\frac{2 \pi t}{198}\right)+A_{5} \cos \left(\frac{2 \pi t}{28.286}\right)+B_{5} \sin \left(\frac{2 \pi t}{28.286}\right)+e_{t}, \quad t=1,2, \ldots, n
\end{aligned}
$$

Parameter estimations of the above equations with their significant levels are given in the Table 8.

\begin{tabular}{|c|c|c|c|c|}
\hline Variable & $\begin{array}{l}\text { Degree of } \\
\text { Freedom }\end{array}$ & $\begin{array}{c}\text { Parameter } \\
\text { Estimate }\end{array}$ & Standard Error & t-Values- \\
\hline$\mu$ & 1 & 10.72551 & 0.25107 & $42.72^{*}$ \\
\hline $\mathrm{A}_{1}$ & 1 & 0.27679 & 0.35506 & 0.78 \\
\hline $\mathrm{B}_{1}$ & 1 & -4.24295 & 0.35506 & $-11.95^{*}$ \\
\hline $\mathrm{A}_{2}$ & 1 & -1.58403 & 0.35506 & $-4.46^{*}$ \\
\hline $\mathrm{B}_{2}$ & 1 & -2.80259 & 0.35506 & $-7.89 *$ \\
\hline$A_{3}$ & 1 & -0.47051 & 0.35506 & -1.33 \\
\hline $\mathrm{B}_{3}$ & 1 & -2.22212 & 0.35506 & $-6.26^{*}$ \\
\hline $\mathrm{A}_{4}$ & 1 & 1.59353 & 0.35506 & $4.49 *$ \\
\hline $\mathrm{B}_{4}$ & 1 & -1.28622 & 0.35506 & -3.62 \\
\hline $\mathrm{A}_{5}$ & 1 & -0.70288 & 0.35506 & -1.98 \\
\hline $\mathrm{B}_{5}$ & 1 & 1.69554 & 0.35506 & $4,78 *$ \\
\hline$\mu$ & 1 & 10.62338 & 0.23529 & $45.15 *$ \\
\hline $\mathrm{A}_{1}$ & 1 & 0.26928 & 0.33275 & 0.81 \\
\hline $\mathrm{B}_{1}$ & 1 & -4.03992 & 0.33275 & $-12.14^{*}$ \\
\hline $\mathrm{A}_{2}$ & 1 & -1.41525 & 0.33275 & $-4.25^{*}$ \\
\hline $\mathrm{B}_{2}$ & 1 & -2.65303 & 0.33275 & $-7.98 *$ \\
\hline $\mathrm{A}_{3}$ & 1 & -0.44517 & 0.33275 & -1.34 \\
\hline $\mathrm{B}_{3}$ & 1 & -2.17120 & 0.33275 & $-6.52 *$ \\
\hline $\mathrm{A}_{4}$ & 1 & 1.67373 & 0.33275 & $5.03 *$ \\
\hline $\mathrm{B}_{4}$ & 1 & -1.32544 & 0.33275 & $-3.98 *$ \\
\hline $\mathrm{A}_{5}$ & 1 & -0.67298 & 0.33275 & -2.02 \\
\hline $\mathrm{B}_{5}$ & 1 & 1.59024 & 0.33275 & $4.78 *$ \\
\hline$\mu$ & 1 & 11.35283 & 0.45914 & $24.73^{*}$ \\
\hline $\mathrm{A}_{1}$ & 1 & -5.21157 & 0.64932 & $-8.03 *$ \\
\hline $\mathrm{B}_{1}$ & 1 & -4.11439 & 0.64932 & $-6.34 *$ \\
\hline$A_{2}$ & 1 & -0.79037 & 0.64932 & -1.22 \\
\hline $\mathrm{B}_{2}$ & 1 & 3.62226 & 0.64932 & $5.58 *$ \\
\hline $\mathrm{A}_{3}$ & 1 & -1.10158 & 0.64932 & 1.70 \\
\hline $\mathrm{B}_{3}$ & 1 & -3.22752 & 0.64932 & $-4.97 *$ \\
\hline $\mathrm{A}_{4}$ & 1 & 0.93764 & 0.64932 & 1.44 \\
\hline $\mathrm{B}_{4}$ & 1 & -1.12744 & 0.64932 & -1.74 \\
\hline $\mathrm{A}_{5}$ & 1 & -0.19683 & 0.64932 & -0.30 \\
\hline $\mathrm{B}_{5}$ & 1 & -3.09203 & 0.64932 & $-4.76^{*}$ \\
\hline$\mu$ & 1 & 12.24884 & 0.93749 & $13.07 *$ \\
\hline $\mathrm{A}_{1}$ & 1 & -6.64940 & 1.32580 & $-5.02 *$ \\
\hline $\mathrm{B}_{1}$ & 1 & -7.82977 & 1.32580 & $-5.91 *$ \\
\hline $\mathrm{A}_{2}$ & 1 & 7.43745 & 1.32580 & $5.61 *$ \\
\hline
\end{tabular}

Table 8. Parameter estimation of the proposed models 
Table 8. (Continued).

\begin{tabular}{|c|c|c|c|c|}
\hline $\mathrm{B}_{2}$ & 1 & -1.93446 & 1.32580 & -1.46 \\
\hline $\mathrm{A}_{3}$ & 1 & 1.29876 & 1.32580 & 0.98 \\
\hline $\mathrm{B}_{3}$ & 1 & 7.11175 & 1.32580 & $5.36^{*}$ \\
\hline $\mathrm{A}_{4}$ & 1 & -5.23507 & 1.32580 & -3.95 \\
\hline $\mathrm{B}_{4}$ & 1 & -4.49714 & 1.32580 & -3.39 \\
\hline $\mathrm{A}_{5}$ & 1 & 1.70227 & 1.32580 & 1.28 \\
\hline $\mathrm{B}_{5}$ & 1 & 6.46418 & 1.32580 & $4.88^{*}$ \\
\hline & & & & $39.45^{*}$ \\
\hline$\mu$ & 1 & 11.32361 & 0.28704 & $-11.33^{*}$ \\
\hline $\mathrm{A}_{1}$ & 1 & -4.60085 & 0.40593 & $-4.16^{*}$ \\
\hline $\mathrm{B}_{1}$ & 1 & -1.68824 & 0.40593 & $-37^{*}$ \\
\hline $\mathrm{A}_{2}$ & 1 & 2.98987 & 0.40593 & -2.41 \\
\hline $\mathrm{B}_{2}$ & 1 & -2.19021 & 0.40593 & $-6.82^{*}$ \\
\hline $\mathrm{A}_{3}$ & 1 & -0.97778 & 0.40593 & 1.64 \\
\hline $\mathrm{B}_{3}$ & 1 & -2.76919 & 0.40593 & -1.43 \\
\hline $\mathrm{A}_{4}$ & 1 & 0.66562 & 0.40593 & $-6.32^{*}$ \\
\hline $\mathrm{B}_{4}$ & 1 & -0.57864 & 0.40593 & 0.38 \\
\hline $\mathrm{A}_{5}$ & 1 & -2.56622 & 0.40593 & \\
\hline $\mathrm{B}_{5}$ & 1 & 0.15502 & 0.40593 & \\
\hline$* *$ and $* * *$ & represents $1 \%, 5 \%$ and $10 \%$ significance level respectively. & \\
\hline
\end{tabular}

In the Table 8. insignificant parameters which are determined by the t-test are given in bold. Here, standard t-test is used because the investigated series are stationary. We reestimate the above models by removing insignificant parameters. They are as follows:

$$
\begin{aligned}
\hat{X}_{t}= & 10.72551-4.24295 \sin \left(\frac{2 \pi t}{66}\right)-1.58403 \cos \left(\frac{2 \pi t}{49.5}\right)-2.80259 \sin \left(\frac{2 \pi t}{49.5}\right)-2.22212 \sin \left(\frac{2 \pi t}{99}\right) \quad(15) \\
& +1.59353 \cos \left(\frac{2 \pi t}{198}\right)-1.28622 \sin \left(\frac{2 \pi t}{198}\right)-0.70288 \cos \left(\frac{2 \pi t}{24.75}\right)+1.69554 \sin \left(\frac{2 \pi t}{24.75}\right), \quad t=1,2, \ldots
\end{aligned}
$$

$$
\begin{aligned}
\hat{X}_{1, t}= & 10.62338-4.03992 \sin \left(\frac{2 \pi t}{66}\right)-1.41525 \cos \left(\frac{2 \pi t}{49.5}\right)-2.65303 \sin \left(\frac{2 \pi t}{49.5}\right)-2.17120 \sin \left(\frac{2 \pi t}{99}\right) \\
& +1.67373 \cos \left(\frac{2 \pi t}{198}\right)-1.32544 \sin \left(\frac{2 \pi t}{198}\right)-0.67298 \cos \left(\frac{2 \pi t}{24.75}\right)+1.59024 \sin \left(\frac{2 \pi t}{24.75}\right), \quad t=1,2, \ldots, n
\end{aligned}
$$$$
\hat{X}_{2, t}=11.35283-5.21157 \cos \left(\frac{2 \pi t}{49.5}\right)-4.11439 \sin \left(\frac{2 \pi t}{49.5}\right)+3.62226 \sin \left(\frac{2 \pi t}{22}\right)-3.22752 \sin \left(\frac{2 \pi t}{99}\right) \quad(17
$$$$
-3.09203 \sin \left(\frac{2 \pi t}{66}\right), \quad t=1,2, \ldots, n
$$

$$
\begin{aligned}
\hat{X}_{3, t}= & 12.24884-6.64950 \cos \left(\frac{2 \pi t}{49.5}\right)-7.82977 \sin \left(\frac{2 \pi t}{49.5}\right)+7.43745 \cos \left(\frac{2 \pi t}{22}\right)+7.11175 \sin \left(\frac{2 \pi t}{22}\right) \quad(18) \\
& -5.23507 \cos \left(\frac{2 \pi t}{66}\right)-4.79714 \sin \left(\frac{2 \pi t}{66}\right)+6.46418 \sin \left(\frac{2 \pi t}{7.92}\right)+e_{t}, \quad t=1,2, \ldots, n
\end{aligned}
$$




$$
\begin{aligned}
\hat{X}_{4, t}= & 11.32361-4.60085 \cos \left(\frac{2 \pi t}{49.5}\right)-1.68824 \sin \left(\frac{2 \pi t}{49.5}\right)+2.98987 \cos \left(\frac{2 \pi t}{66}\right)-2.19021 \sin \left(\frac{2 \pi t}{66}\right)(19) \\
& -0.97778 \cos \left(\frac{2 \pi t}{99}\right)-2.76919 \sin \left(\frac{2 \pi t}{99}\right)-2.56623 \cos \left(\frac{2 \pi t}{28.286}\right), \quad t=1,2, \ldots, n
\end{aligned}
$$

It should be noted that general food inflation and $\mathrm{X}_{1}$ series has the same periodicities with the same orders. Also, significant parameters are same. Thus, it can be concluded that $\mathrm{X}_{1}$ affects intensively general food inflation. By using the above estimated models, we have forecasted the ratios of the next year's monthly inflations. These forecasts are given in the Table 9.

Table 9. Forecasted values of the time series from 2020:07 to 2021:06

\begin{tabular}{|c|l|l|l|l|l|}
\hline Year/Month & \multicolumn{1}{|c|}{$\mathbf{X}$} & \multicolumn{1}{|c|}{$\mathbf{X}_{\mathbf{1}}$} & \multicolumn{1}{|c|}{$\mathbf{X}_{\mathbf{2}}$} & \multicolumn{1}{|c|}{$\mathbf{X}_{\mathbf{3}}$} & $\mathbf{X}_{\mathbf{4}}$ \\
\hline $2020: 07$ & 9.5526 & 9.74075 & 5.25105 & 8.9527 & 5.63624 \\
\hline $2020: 08$ & 9.1230 & 9.31915 & 4.45460 & 9.9512 & 5.26741 \\
\hline $2020: 09$ & 8.7228 & 8.92489 & 3.79491 & 10.7068 & 5.05372 \\
\hline $2020: 10$ & 8.337 & 8.53892 & 3.30858 & 11.1435 & 4.97780 \\
\hline $2020: 11$ & 7.9313 & 8.14402 & 3.02327 & 11.2044 & 5.01467 \\
\hline $2020: 12$ & 7.5068 & 7.72628 & 2.95574 & 10.8563 & 5.13380 \\
\hline $2021: 01$ & 7.0485 & 7.27633 & 3.11066 & 10.0921 & 5.30138 \\
\hline $2021: 02$ & 6.5513 & 6.79028 & 3.48006 & 8.9319 & 5.48283 \\
\hline $2021: 03$ & 6.0185 & 6.27022 & 4.04372 & 7.4223 & 5.64538 \\
\hline $2021: 04$ & 5.4586 & 5.72430 & 4.77026 & 5.6338 & 5.76046 \\
\hline $2021: 05$ & 4.8855 & 5.16636 & 5.61896 & 3.6570 & 5.80582 \\
\hline $2021: 06$ & 4.3200 & 4.61519 & 6.54228 & 1.5974 & 5.76720 \\
\hline
\end{tabular}

\section{Conclusion}

Food and non-alcoholic beverages main group directly affects the food subgroup for that reason it may have the same cycles. The facts that the food subgroup consists of approximately $93 \%$ of the weight in the main group and the ratio of the number of products are more than non-alcoholic beverages subgroup makes the food group the determinative subgroup in the main group.

In this study subgroups of food inflation are investigated by employing harmonic regression. The harmonic regression has the ability to forecast more accurately compared to ARIMA when the time series contains hidden cycles called periodicities. Also, the unit root test based on periodograms are used to test the stationarity of the time series. It is revealed that subgroups of food and non-alcohol beverages, unprocessed food, fruit and vegetables and other unprocessed food are stationary while the others are non-stationary.

As a result of the analysis, it has been observed that processed food products are not stationary, and unprocessed food products are stationary. Unprocessed food prices are stationary due to the lack of import dependency in vegetables and fruit products included in the CPI basket and the lack of changes in terms of climate conditions. Using the forecast models in the study, it is possible to predict the monthly inflation rates of 
the following year, and especially revealing the cycle in food inflation reveals a result that should be taken into account in planning in the field of economic policies.

In terms of processed food products, it is striking that leg of packaged and processed food products has an important share. Considering the legumes and oil groups in particular, the use of imports with an alternative pricing policy to domestic market prices makes processed food prices dependent on foreign currency. Changes in international prices are likely to be reflected in domestic food prices through the expectation channel, as well as through the import channel. The reason for the low price elasticity of the demand for food products in the processed food subgroup, which is the determinant of food prices, and especially the price determination policies of discount markets, the increases in producer prices can be reflected in consumer prices in a short time.

As a possible field of study, an analysis can be made using inflation data containing different periods. The policies implemented can be examined by comparing the inflation data of different countries with the inflation data of Turkey.

The policy makers can use the information revealed by this study to fight against inflations. It is shown that the food inflations have 2 years cycle which is mostly driven by the subgroups of food inflation. In order to take control main inflation, the inflation on subgroups of food should be brought under control. The reasons behind the two year cycles should be investigated by the policy makers. Also, it is shown that the fluctuations in gasoline and diesel prices, because of the dependency on exchange rates and import regimes do not make the processed food group a stationary series. The nonstationarity behavior of the time series imply that it is not possible to forecast the time series in the level. Thus it creates uncertainty for the government. The cause of this situation is obvious, thus more incentives on animal husbandry and farming may solve the problem.

\section{References}

[1] Adam, C., Kwimbere, D., Mbowe, W., O'Connell, S., Food Prices and Inflation in Tanzania. Journal of African Development, 18(2), 19-40, (2016).

[2] Akdi, Y., \& Dickey, D. A., Periodograms of unit root time series: distributions and tests. Communications in Statistics-Theory and Methods, 27(1), 69-87, (1998).

[3] Akdi, Y., Okkaoğlu, Y., Gölveren, E., \& Yücel, M. E., Estimation and forecasting of PM 10 air pollution in Ankara via time series and harmonic regressions. International Journal of Environmental Science and Technology, 1-14, (2020a).

[4] Akdi, Y., Gölveren, E., \& Okkaoğlu, Y., Daily electrical energy consumption: Periodicity, harmonic regression method and forecasting. Energy, 191, 116524, (2020b).

[5] Akdi, Y., Varlik, S., \& Berument, M. H., Duration of Global Financial Cycles. Physica A: Statistical Mechanics and its Applications, 124331, (2020c).

[6] Agrawal, P., Kumarasamy, D., Food Price Inflation in India: Causes and Cures. Indian Economic Review, 49(1), 57-84, (2014). 
[7] Altissimo, F., Ehrmann, M., Smets, F., Inflation Persistence and Price-Setting Behavior in the Euro Area, European Central Bank, Occasional Paper Series, No. 46, (2006).

[8] Bronnenberg, B., Mela, C., Boulding, W. The Periodicity of Pricing, Journal of Marketing Research, 43(3), 477-493. (2006).

[9] Durevalla, D., Loening, J.L, Birru, Y.A., Inflation dynamics and food prices in Ethiopia, Journal of Development Economics, 104, 89-106, (2013).

[10] Franses, P.H., Ooms, M., A periodic long-memory model for quarterly UK inflation. International Journal of Forecasting, 13(1), March, 117-126, (1997).

[11] Fuller, W. A., Introduction to statistical time series, Wiley, NewYork, (1996).

[12] Gómez, M.I., González, E., Melo, L., Torres, J.L., Forecasting Food Price Inflation in Developing Countries with Inflation Targeting Regimes: The Colombian Case, American Agricultural Economics Association Annual Meeting, (2006).

[13] Hafer, R., Hein, S., On the Accuracy of Time-Series, Interest Rate, and Survey Forecasts of Inflation, The Journal of Business, 58(4), 377-398, (1985).

[14] Hanif, M.N., A Note on Food Inflation in Pakistan, Pakistan Economic and Social Review, 50, No. 2, 183-206, (2012).

[15] Hasanov, M. Effects of Inflation Uncertainty on Output: The Case of Turkey, Journal of Doğuş University, (In Turkish), 2, (2008).

[16] Gil-Alana, L.A., Trani, T., The cyclical structure of the UK inflation rate: 12102016, Economics Letters, Elsevier, 181(C), 182-185, (2019).

[17] Ida, D., Sectoral inflation persistence and optimal monetary policy, Journal of Macroeconomics, 65, (2020).

[18] Joiya, S.A., Shahzad, A.A., Determinants of High Food Prices: The Case of Pakistan, Pakistan Economic and Social Review, Department of Economics, University of the Punjab, 51, No. 1 (Summer 2013), 93-107, (2013).

[19] Kang, S.H., Lahmiri, S., Uddin, G.S, Hernandez, J.A., Yoon, S.M., Inflation cycle synchronization in ASEAN countries, Physica A: Statistical Mechanics and its Applications, 545, (2020).

[20] Lamm, R. M., Dynamics of Food Price Inflation, Western Journal of Agricultural Economics, 4, No. 2 (December 1979), 119-132, (1979).

[21] Okkaoğlu, Y., Akdi, Y., Ünlü, K. D., Daily PM10, periodicity and harmonic regression model: The case of London, Atmospheric Environment, 117755, (2020).

[22] Safouane, M., Aïssaab, B., Musyc, O., Pereaud, J.C., Modelling inflation persistence with periodicity changes in fixed and predetermined prices models, Economic Modelling, 24, Issue 5, September 2007, 823-838, (2007).

[23] Salisu, A.A., Kazeem, O.I., Predicting US inflation: Evidence from a new approach. Economic Modelling, 71, 134-158, (2018).

[24] Schnepf, R., Richardson, J., Consumers and food price inflation, Congressional Research Service, Library of Congress, (2012).

[25] Van D.C., Food Prices, Expectations, and Inflation, American Journal of Agricultural Economics, 64(3), 419-430, (1982).

[26] Wei, W. W.S., Time Series Analysis: Univariate and Multivariate Methods, Second Edition, Pearson Addision Wesley, Boston, (2006). 